\title{
Follow-Up Study of a Multiple Myeloma Patient Successfully Treated with Clarithromycin (CAM), Low-Dose Lenalidomide and Low-Dose Dexamethasone: Significance and Possible Mechanism of Action of CAM as an Add-On Therapy
}

\author{
Nobuo Takemori1, Toshio Fukuda², Masaru Kojima ${ }^{3}$ \\ ${ }^{1}$ Division of Hematology, Internal Medicine, Imai Hospital, Ashikaga, Japan \\ ${ }^{2}$ Graduate School of Health Sciences, Gunma University, Maebashi, Japan \\ ${ }^{3}$ Department of Anatomic and Diagnostic Pathology, Dokkyo Medical University School of Medicine, \\ Shimotsuga-gun, Japan \\ Email: takemori nobuo@circus.ocn.ne.jp
}

Received 16 November 2014; revised 10 December 2014; accepted 25 December 2014

Copyright (C) 2014 by authors and Scientific Research Publishing Inc.

This work is licensed under the Creative Commons Attribution International License (CC BY). http://creativecommons.org/licenses/by/4.0/

\section{(c) (i) Open Access}

\section{Abstract}

Background: Recently, high efficacy of the chemotherapeutic regimen combining clarithromycin (CAM) with lenalidomide (Len) and dexamethasone (Dex) (BiRD) in treating multiple myeloma (MM) patients has been reported. However, the exact mechanism of added CAM has not been fully elucidated. This case report will provide helpful information for understanding the significance and the mechanism of action of CAM as an add-on therapy. Patient: A 78-year-old female patient with IgA- $\lambda$ type MM was treated with low-dose Len coupled with low-dose Dex (low Rd), and excellent response was achieved for long term, but she later became refractory to this treatment. Then, CAM was added to low Rd (low Rd-CAM, i.e., modified BiRD therapy). This add-on-therapy was found to be effective, but later suspended because of pneumonitis. Then, low-dose Len coupled with CAM (low R-CAM) treatment was applied; but effect of this Dex-free treatment was insufficient. Thus, low Rd-CAM was reapplied and satisfactory reduction of IgA was achieved. This fact suggests that low Rd-CAM is the favorable combination, Dex is requisite and CAM might have enhanced the effect of Dex. In this case, various serum cytokines were examined during the course

How to cite this paper: Takemori, N., Fukuda, T. and Kojima, M. (2014) Follow-Up Study of a Multiple Myeloma Patient Successfully Treated with Clarithromycin (CAM), Low-Dose Lenalidomide and Low-Dose Dexamethasone: Significance and Possible Mechanism of Action of CAM as an Add-On Therapy. Case Reports in Clinical Medicine, 3, 674-684. 
of illness. Only interleukin-6 showed apparent increase, and tumor necrosis factor- $\alpha$, transforming growth factor- $\beta$, soluble-IL-2 receptors and C-reactive protein showed the slight increase during low Rd-CAM treatment. The results seem somewhat conflicting, but it seems that intricate cytokine response due to immune activation might have occurred during low Rd-CAM treatment.

\title{
Keywords
}

\author{
Follow-Up Study, Multiple Myeloma, Clarithromycin (CAM), Lenalidomide, Dexamethasone, \\ Significance, Mechanism of Action of CAM, Add-On Therapy
}

\section{Introduction}

Lenalidomide (Len) $\left(\right.$ Revlimid $\left.^{\circledR}\right)$, a derivative of thalidomide, has begun to be used in combination with dexamethasone (Dex) for treating refractory or relapsed [1] [2] and newly diagnosed [3]-[7] multiple myeloma (MM). Recently, high efficacy of the chemotherapeutic regimen combining clarithromycin (CAM) (Biaxin $\left.{ }^{\circledR}\right)$ with Len and Dex (BiRD regimen) in treating MM has been reported [4] [8] [9]. However, the exact mechanism of action of added CAM has not been fully elucidated. CAM, a member of macrolide family, is a widely used antibacterial drug. It is also known to have other important pharmacological effects such as immunosuppression or immunomodulation [10] [11]. We describe herein subsequent successful add-on therapy of CAM in a case of IgA- $\lambda$ type MM treated with low-dose Len and low-dose Dex (low Rd). To elucidate the mechanism of action of CAM, we examined various serum cytokines during the course of illness and analyzed the clinical course with special reference to CAM as an add-on therapy. Possible mechanisms of action of CAM, Dex as well as Len in the treatment of MM are discussed.

\section{Case Presentation}

A 78-year-old Japanese woman $(29 \mathrm{~kg} / 145 \mathrm{~cm})$ with a 26 -year history of hypertension was referred to Imai Hospital from a local clinic on June 6, 2009 because of severe anemia and general weakness. She is congenitally deaf and mute and had moderate mental retardation. Her family history was unknown because she had no relatives. Physical examination on admission revealed that she was undernourished and remarkably dehydrated. The temperature was $38.5^{\circ} \mathrm{C}$, the pulse was 120 per minute, irregular and weak, and the blood pressure was 85/60. A complete blood cell count showed remarkable anemia (red blood cell count, $1.60 \times 10^{12} / \mathrm{L}$; hemoglobin 4.1 $\mathrm{g} / \mathrm{dL}$ ), leukocytosis (white blood cell count, $19.8 \times 10^{9} / \mathrm{L}$ with $93 \%$ neutrophils, $4 \%$ lymphocytes and 3\% monocytes) and normal platelet count $\left(259 \times 10^{9} / \mathrm{L}\right)$. Elevated levels of erythrocyte sedimentation rate $(\geq 110 \mathrm{~mm} / \mathrm{hr}$; normal range [nr]. 3 - $15 \mathrm{~mm} / \mathrm{hr}$ ), CRP (7.65 mg/dL; nr. 0 - $0.26 \mathrm{mg} / \mathrm{dL})$, AST (50 IU/L; nr. 8 - $38 \mathrm{IU} / \mathrm{L})$, LDH (392 IU/L; nr. 106 - 211 IU/L), CPK (1090 IU/L; nr. 45 - 175 IU/L), BUN (42.7 mg/dL; nr. 8.0 - 20.0 mg/dL), creatinine $(1.04 \mathrm{mg} / \mathrm{dL}$; nr. $0.4-0.8 \mathrm{mg} / \mathrm{dL})$, uric acid $(11.7 \mathrm{mg} / \mathrm{dL}$; $\mathrm{nr}$. $2.5-7.0 \mathrm{mg} / \mathrm{dL})$, total protein $(8.7 \mathrm{~g} / \mathrm{dL}$; nr. 6.7 - $8.3 \mathrm{~g} / \mathrm{dL}$ ), $\beta_{2}$-microglobulin $(8.2 \mathrm{mg} / \mathrm{L}$; nr. 0.9 - $1.9 \mathrm{mg} / \mathrm{L}$ ), soluble-IL-2 receptors (s-IL-2R) (766 IU/mL; nr. 124 - $466 \mathrm{IU} / \mathrm{mL})$, immunoglobulin (Ig) A (4820 mg/dL; nr. 110 - $410 \mathrm{mg} / \mathrm{dL}$ ) and serum osmotic pressure (315 mOsm/kg; nr. 275 - $290 \mathrm{mOsm} / \mathrm{kg}$ ), and reduced levels of serum Fe (34 $\mu \mathrm{g} / \mathrm{dL} ; \mathrm{nr} .54$ - $181 \mu \mathrm{g} / \mathrm{dL}$ ), albumin (2.2 g/dL; nr. 3.9 - 4.9 g/dL), ZTT (1 KU; nr. 4 - 12 KU), IgG (255 mg/dL; nr. 870 - 1700 mg/dL), IgM (18 $\mathrm{mg} / \mathrm{dL}$; nr. 46 - $1700 \mathrm{mg} / \mathrm{dL})$ and total cholesterol (111 mg/dL; nr. $130-219 \mathrm{mg} / \mathrm{dL})$ were observed. IgA- $\lambda$ type M-protein was detected in the serum by immunoelectrophoresis. The urine showed proteinuria and $\lambda$-type Bence-Jones protein. Rheumatoid arthritis particle agglutination titer, and anti-nuclear, anti-microsome and anti-thyroglobulin antibody titers were within normal limits. An electrocardiogram showed frequent ventricular premature contractions and ischemic changes. An abdominal computed tomography (CT) scan revealed a right lower abdominal osteolytic tumor approximately $7 \mathrm{~cm}$ in diameter originated from the right iliac bone marrow and multiple osteolytic lesions in the lumbar vertebrae, ilium and sacrum (Figure 1). Skull x-ray films showed multiple punched out lesions.

The sternal puncture carried out on admission showed that the bone marrow was infiltrated by typical myeloma cells accounting for $37.6 \%$ of total nucleated cells on smear preparation. Immunohistochemically, they were, though faint, positive for IgA and light chain $\lambda$ (Figure 2), but negative for cyclin D1 and almost negative 


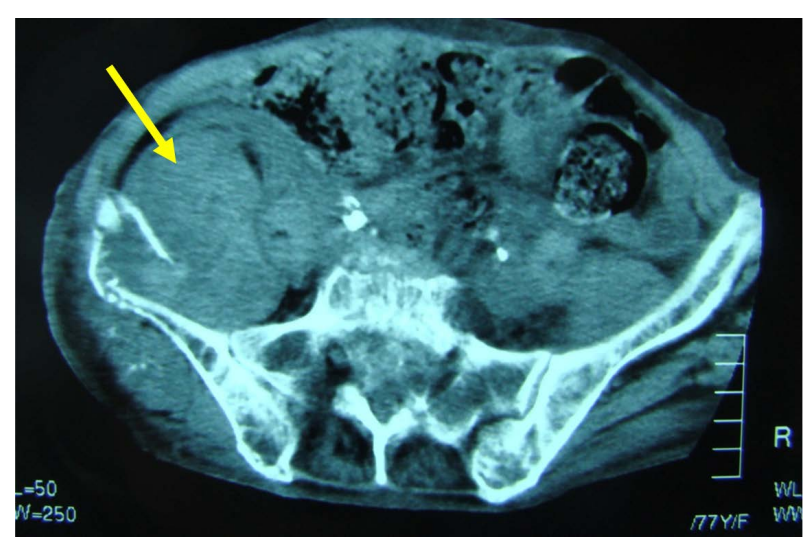

Figure 1. CT scan of the abdomen and pelvis showing osteolytic soft tissue mass (arrow) originated from iliac bone.

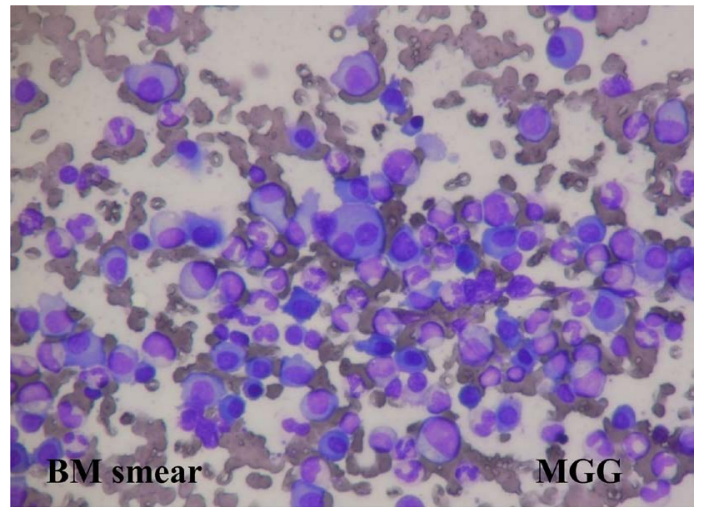

(a)

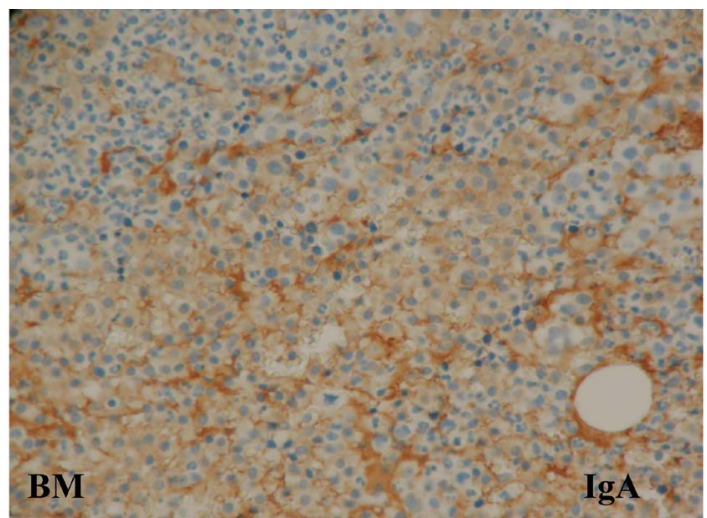

(c)

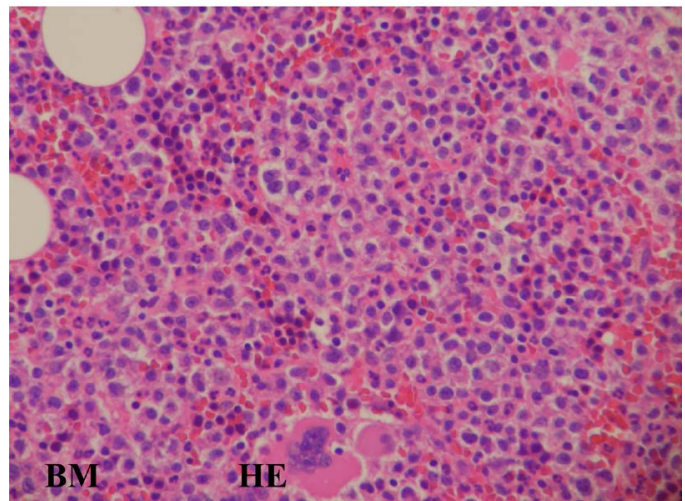

(b)

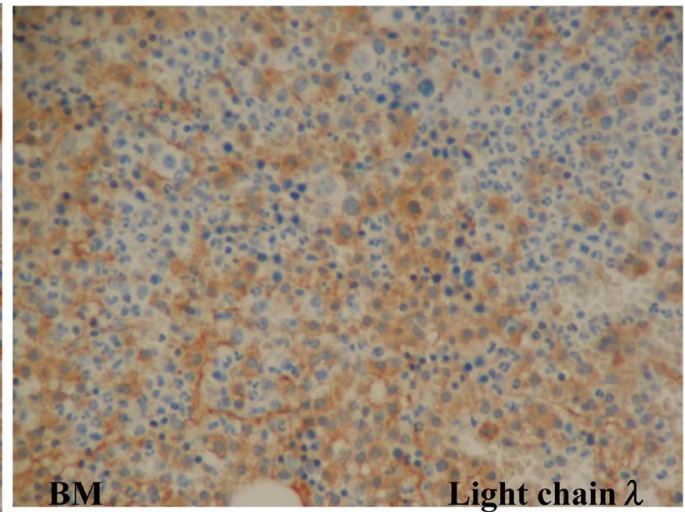

(d)

Figure 2. BM on admission. (a) BM smear (MGG stain). BM was infiltrated by typical myeloma cells showing basophilic cytoplasm with inconspicuous nucleoli (under 40× magnification objective); (b) BM clot section (HE stain). BM showed extensive myeloma cell infiltration (under 40× magnification objective); (c) BM clot section immunostained for IgA. Myeloma cells were slightly positive for IgA (under 40× magnification objective); (d) BM clot section immunostained for light chain $\lambda$. Myeloma cells were slightly positive for light chain $\lambda$ (under $40 \times$ magnification objective). Abbreviations: BM, bone marrow; HE, hematoxylin and eosin; MGG, May Grünwald-Giemsa.

for Ki-67 antigen (not shown), indicating that the myeloma cells had depressed mitotic ability. No amyloid deposition was confirmed in the bone marrow by Congo red staining. The chromosomal analysis of the bone marrow cells revealed a normal karyotype; however, FISH analysis of the bone marrow, which was later carried out, 
revealed IGH/FGFR3 fusion signals in myeloma cells. Thus the diagnosis of IgA- $\lambda$ type multiple myeloma (Durie and Salmon: stage II, International Staging System: stage III, Southwest Oncology Group: stage IV), rhabdomyolysis, dehydration, unknown infection and ischemic heart disease with ventricular premature contractions was made.

In this case, the intravenous infusion of fluids and antibiotics was initiated on the day of admission. After the initiation of this treatment, her fever subsided, CRP values returned to normal, and the rhabdomyolysis and dehydration were improved within two weeks. Initially, melphalan coupled with prednisolone (PSL) treatment was started on June 13, 2009 (Figure 3). This treatment was effective and IgA levels decreased from $4820 \mathrm{mg} / \mathrm{dL}$ to $2800 \mathrm{mg} / \mathrm{dL}$ after one cycle of the treatment. However, the treatment was discontinued because she became defiant and uncooperative to the treatment. Thus, a single interferon (IFN)- $\alpha$ therapy was applied on July 7, 2009, but this treatment was ineffective. Then, the treatment consisting of melphalan, Dex and IFN- $\alpha$ was applied. This treatment was effective and levels of IgA decreased to $1066 \mathrm{mg} / \mathrm{dL}$ on January 5, 2011. This treatment was again discontinued because she became defiant and uncooperative. Afterwards, IgA gradually increased to 3660 $\mathrm{mg} / \mathrm{dL}$ on July 1, 2011. Then, the treatment of low-dose Len coupled with low-dose Dex (low Rd) (Len at a dose of $10 \mathrm{mg}$ per day on days 1 to 21, plus Dex at a dose of $20 \mathrm{mg}$ per day on days 1, 8, 15) at 4-week intervals was initiated from July 1, 2011. This treatment was found to be very effective; the levels of IgA rapidly decreased from $3660 \mathrm{mg} / \mathrm{dL}$ to normal limits after 3 cycles of low Rd treatment. However, after finishing 16 cycles of low Rd treatment, herpes zoster (HZ) developed on her left flank and back in early December, 2012. Thus, this treatment was temporarily suspended. The cessation of low Rd treatment resulted in gradual increase of serum IgA up to $649 \mathrm{mg} / \mathrm{dL}$ (detailed clinical course after HZ infection is shown in Figure 4). After improving HZ, low Rd treatment was restarted on January 8, 2013, and serum IgA levels returned to normal. However, after finishing 13 cycles (total 26 cycles) of low Rd treatment, IgA levels gradually started to increase up to $618 \mathrm{mg} / \mathrm{dL}$, indicating the acquisition of refractoriness to the treatment. Then, CAM (a dose of $400 \mathrm{mg}$ per day, $200 \mathrm{mg}$ twice a day, on days 1 to 21 for 4-week intervals) was added to low Rd treatment on January 8, 2014. This add-on therapy (i.e., low Rd-CAM) was found to be effective; IgA levels rapidly returned to $190 \mathrm{mg} / \mathrm{dL}$ after two cycles of the treatment. However, this treatment was discontinued because of severe pneumonitis. During the cessation of the treatment, IgA gradually increased up to $946 \mathrm{mg} / \mathrm{dL}$ (April 7, 2014). After improving pneumonitis, the

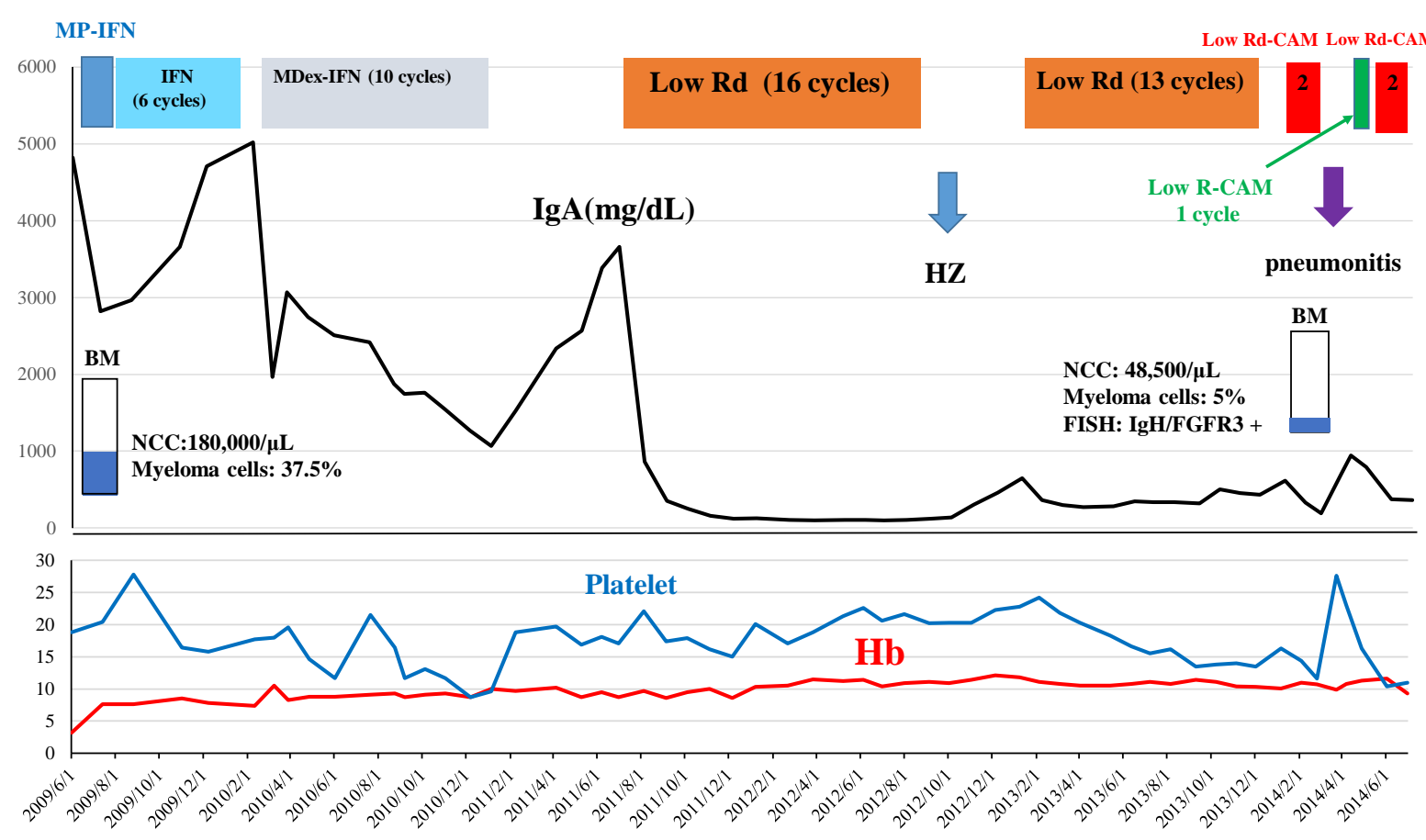

Figure 3. Whole clinical course of the patient. Remarkable depression of serum IgA levels occurred after the initiation of low Rd treatment and the partial response (PR) according to the criteria of International Myeloma Working Group (IMWG) has been maintained afterwards. Abbreviations: BM, bone marrow; CAM, clarithromycin; HZ, herpes zoster; IFN, interferon; MDex, melphalan and dexamethasone; Rd, lenalidomide and dexamethasone; NCC, nuclear cell count. 


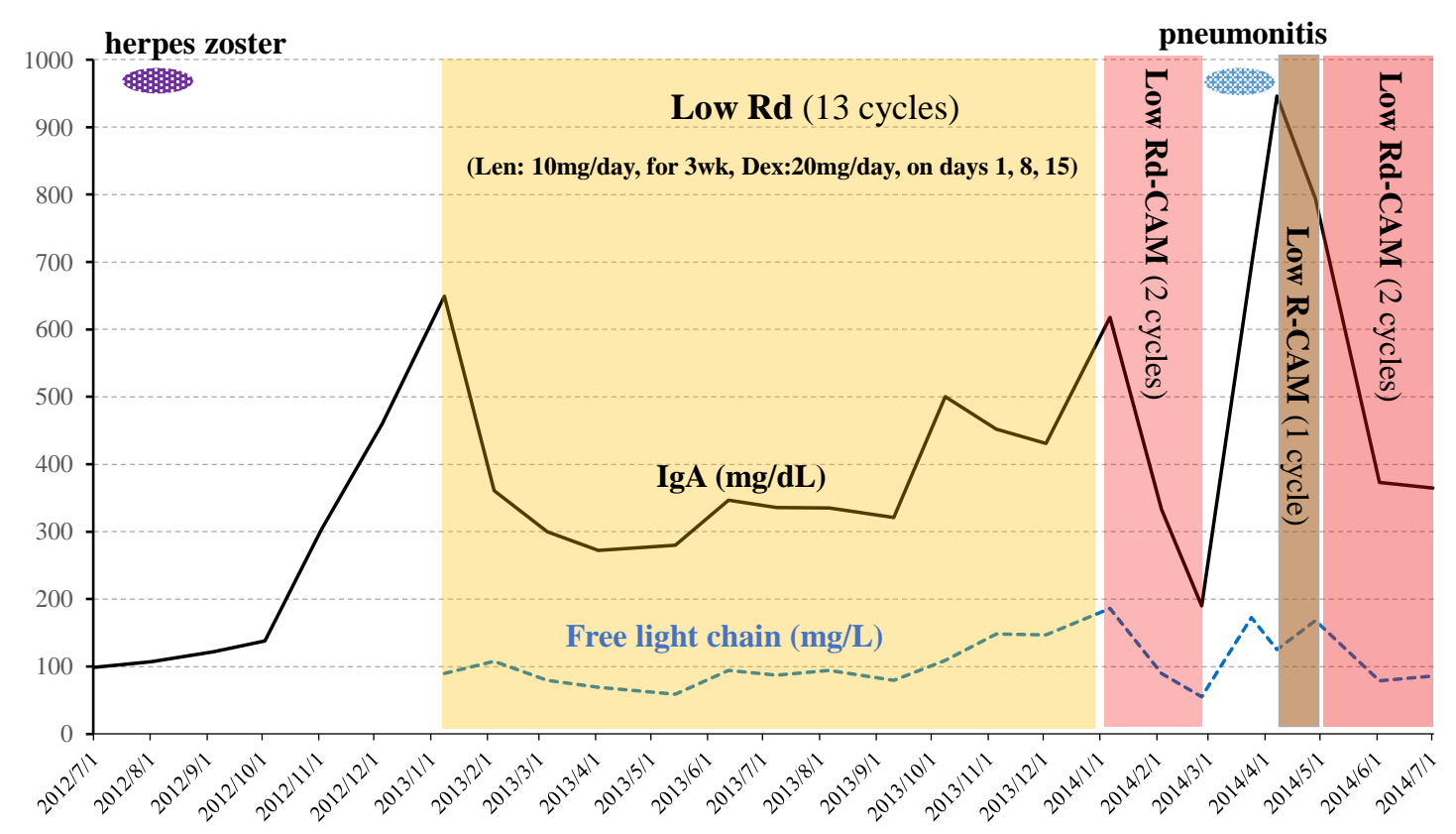

Figure 4. Detailed clinical course after herpes zoster infection. During the treatment with low Rd, serum IgA levels gradually started to increase, indicating acquisition of refractoriness to low Rd. Subsequent low Rd-CAM resulted in remarkable decrease of IgA, but this treatment was discontinued because of pneumonitis. After improving pneumonitis, low R-CAM was applied, but this was somewhat insufficient for reducing IgA. Subsequently, low Rd-CAM applied again, and this resulted in satisfactory reduction of IgA. Abbreviations: CAM, clarithromycin; R-CAM, lenalidomide plus CAM; Rd, lenalidomide and dexamethasone; Rd-CAM, Rd plus CAM.

treatment combined with low-dose Len and CAM (i.e., low R-CAM) was applied to avoid the recurrence of pneumonitis on April 12, 2014. However, this Dex-free regimen was found to be somewhat insufficient for reducing IgA; levels of IgA only slightly reduced from $946 \mathrm{mg} / \mathrm{dL}$ to $794 \mathrm{mg} / \mathrm{dL}$ after one cycle of this treatment. Thus, the low Rd-CAM was applied again on May 12, 2014. In contrast, this was found to be effective; levels of IgA rapidly returned to $373 \mathrm{mg} / \mathrm{dL}$ after one cycle of the treatment. Low Rd-CAM treatment has been carried out without unfavorable adverse effects. The IgA values are remained within normal limits (WNL) and BenceJones protein in the urine disappeared as of July 7, 2014. However, slightly elevated levels of $\lambda$-type free light chain (FLC) have remained.

In this case, Th1, Th2 and pro-inflammatory serum cytokines including interleukin (IL)-1 $\beta$, IL-2, IL-4, IL-5, IL-6, IL-10, IL-12, TGF- $\beta$, TNF- $\alpha$ and IFN- $\gamma$ were examined on 5 occasions when no infectious symptom was present (Table 1, Table 2). Unexpectedly, the distinct elevation of IL-6 and slight elevation of TNF- $\alpha$ and TGF$\beta$ were observed during low Rd-CAM treatment (Table 1). Analysis of the relationship between IgA, cytokines and cytokine-related parameters showed that the distinct elevations of IL-6 and slight elevation of TNF- $\alpha$ and TGF- $\beta$ were observed with slight elevations of s-IL-2R and CRP particularly during low Rd-CAM treatment (Table 2).

\section{Discussion}

Generally, Len has been used in combination with Dex for treating refractory or relapsed [1] [2] and newly diagnosed [3]-[7] MM. The precise cellular targets and the exact mechanism of action of immunomodulatory drugs (IMiDs) including Len remain unclear; however, recent studies unveiled multiple effects including 1) immune modulation (CD4+ and CD8+ T-cell co-stimulation, Tregs suppression, Th1 cytokine production, NK and NKT cell activation, antibody-dependent cellular cytotoxicity), 2) interference with tumor micro-environment interactions (anti-angiogenesis, anti-inflammatory properties, downregulation of adhesion molecules and antiosteoclastogenic properties) and 3) direct anti-tumor effects (anti-proliferative activity: inhibition of cyclin-dependent kinase and induced expression of tumor suppressor genes such as Egr-1, Egr-2 and SPARC, downregulation of NF-kB and inhibition of caspase 3, 8 and 9) [12]. Len is known to suppress TNF- $\alpha$ [4] [12] [13], IL-1 $\beta$ 
Table 1. Levels of cytokines during treatment and treatment-free periods.

\begin{tabular}{|c|c|c|c|c|c|c|}
\hline & $\begin{array}{c}\text { 2013.1.8 } \\
\text { Treatment-free }\end{array}$ & $\begin{array}{c}2013.6 .17 \\
\text { Treating } \\
\text { (Low Rd) }\end{array}$ & $\begin{array}{c}2014.2 .3 \\
\text { Treating } \\
\text { (Low Rd-CAM) }\end{array}$ & $\begin{array}{c}2014.4 .7 \\
\text { Treatment-free }\end{array}$ & $\begin{array}{c}2014.6 .2 \\
\text { Treating } \\
\text { (Low Rd-CAM) }\end{array}$ & (Normal range) \\
\hline $\mathrm{IL}-1 \beta(\mathrm{pg} / \mathrm{mL})$ & $<0.125$ & $<0.125$ & 0.27 & $<0.125$ & & $(\leq 0.928)$ \\
\hline IL-2 (pg/mL) & $<15.6$ & $<15.6$ & $<15.6$ & $<15.6$ & $<15.6$ & $(<15.6)$ \\
\hline IL-4 (pg/mL) & & & & $<0.25$ & & $(<0.25)$ \\
\hline IL-5 (pg/mL) & $<3.9$ & & & $<3.9$ & & $(<3.9)$ \\
\hline IL-6 (pg/mL) & 1.27 & 1.49 & $7.33 \uparrow \uparrow$ & $2.52 \uparrow$ & $10.4 \uparrow \uparrow$ & $(\leq 2.41)$ \\
\hline IL-8 (pg/mL) & & & & $<8.0$ & & $(<8.0)$ \\
\hline IL-10 (pg/mL) & $<0.5$ & & & $<0.5$ & & $(<7.05)$ \\
\hline IL-12 (pg/mL) & $<0.78$ & & & $<0.78$ & 1.86 & $(\leq 3.15)$ \\
\hline TNF- $\alpha(\mathrm{pg} / \mathrm{mL})$ & $<0.55$ & $<0.55$ & $2.19 \uparrow$ & 1.07 & 1.48 & $(\leq 1.79)$ \\
\hline TGF- $\beta 1(\mathrm{pg} / \mathrm{mL})$ & & & & 1.35 & $2.27 \uparrow$ & $(0.89-1.80)$ \\
\hline $\mathrm{IFN}-\gamma(\mathrm{pg} / \mathrm{mL})$ & $<1.56$ & $<1.56$ & & 6.94 & 5.59 & $(\leq 20.6)$ \\
\hline
\end{tabular}

$\uparrow$, slight increase; $\uparrow \uparrow$, apparent increase.

Table 2. Levels of IgA, cytokines and related parameters during treating and treatment-free periods.

\begin{tabular}{|c|c|c|c|c|c|c|c|c|c|}
\hline $\begin{array}{c}\text { Date } \\
\text { Unit } \\
\text { Normal range }\end{array}$ & Treatment & $\begin{array}{c}\text { IgA } \\
(\mathrm{mg} / \mathrm{dL}) \\
(110-410)\end{array}$ & $\begin{array}{c}\text { IL-6 } \\
(\mathrm{pg} / \mathrm{mL}) \\
(\leq 2.41)\end{array}$ & $\begin{array}{l}\text { TNF- } \alpha \\
(\mathrm{pg} / \mathrm{mL}) \\
(\leq 1.79)\end{array}$ & $\begin{array}{c}\text { TGF- } \beta \\
(\mathrm{pg} / \mathrm{mL}) \\
(0.89-1.80)\end{array}$ & $\begin{array}{c}\text { s-IL-2R } \\
(\mathrm{U} / \mathrm{mL}) \\
(124-466)\end{array}$ & $\begin{array}{c}\text { CRP } \\
(\mathrm{mg} / \mathrm{dL}) \\
(\leq 0.26)\end{array}$ & $\begin{array}{c}\text { WBC } \\
(/ \mu \mathrm{L}) \\
\left(4-8 \times 10^{3}\right)\end{array}$ & Fever \\
\hline 2013.1.8 & Treatment-free & $649 \uparrow$ & 1.27 & $<0.55$ & NT & 301 & 0.18 & 4500 & Free \\
\hline 2013.6.17 & Low Rd & 287 & 1.49 & $<0.55$ & NT & $484 \uparrow$ & 0.04 & $2400 \downarrow$ & Free \\
\hline 2014.2.3 & Low Rd-CAM & 333 & $7.33 \uparrow \uparrow$ & $2.09 \uparrow$ & NT & $511 \uparrow$ & $3.29 \uparrow$ & 5110 & Free \\
\hline 2014.4 .7 & Treatment-free & $946 \uparrow$ & $2.52 \uparrow$ & 1.07 & 1.35 & 392 & 0.05 & $3920 \downarrow$ & Free \\
\hline 2014.6 .2 & Low Rd-CAM & 373 & $10.4 \uparrow \uparrow$ & 1.48 & $2.27 \uparrow$ & $545 \uparrow$ & $0.83 \uparrow$ & $3900 \downarrow$ & Free \\
\hline
\end{tabular}

$\uparrow$, slight increase; $\uparrow \uparrow$, apparent increase; $\downarrow$, slight decrease.

[4] [13], IL-6 [4] [12]-[14], IL-12 [4] [13], TGF- $\beta$ [12] [14], macrophage inflammatory protein- $\alpha$ (MIP- $\alpha$ ) [12], granulocyte macrophage colony-stimulation factor (GM-CSF) [12] [13], insulin-like growth factor-1 (IGF-1) [13], basic fibroblast growth factor ( $\beta$ FGF) [12], receptor activator of NF- $\kappa$ B ligand (RANKL) [12] and vascular endothelial growth factor (VEGF) [4] [12] [13], and to increase IL-2 [4] [12] [13], IL-10 [4] and IFN- $\gamma$ [4] [12][14]. Inhibition of VEGF by Len may alter the bone marrow microvasculature, thereby making the microenvironment less hospitable for MM cell growth [4]. Recently, Lu et al. reported that Len-bound cereblon acquires the ability to target for proteasomal degradation of two essential B-cell transcription factors in MM, Ikaros family zinc finger proteins 1 and 3 (IKZF1and IKZF3). They analyzed myeloma cell lines and showed that loss of IKZF1 and IKZF3 is both necessary and sufficient for Len's therapeutic effect [15]. Similarly, Krönke et al. reported that Len causes selective ubiquitination and degradation of IKZF1 and IKZF3 by the CRBN-CRL4 ubiquitin ligase. Furthermore, they demonstrated that Len-induced IL-2 production in T cells is due to depletion of IKZF1 and IKZF3 [16].

Recently, CAM has been incorporated into Len·Dex (RD) regimen (i.e., BiRD regimen) for treating MM [4] [8] [9], and higher complete response rates have been obtained. Many investigators have reported its immunosuppressive or immunomodulatory effects of CAM in patients with cancers [17] [18] [20] or tumor-bearing an- 
imals [19] [20]. Briefly, CAM can decrease the production of IL-1 [10] [21] [22], IL-2, [21] [23] [24], IL-5 [21] [23], IL-6 [10] [11] [17] [19] [21] [23] [24], IL-8 [10] [11] [21] [25], IL-10 [18] [20], TNF- $\alpha$ [10] [17] [19] [21] [23] [26], TGF- $\alpha$ [10], TGF- $\beta$ [21] [26] and matrix metalloproteinase 9 [21] [26], and increase the production of IL-4 [19] [21], IL-12 [18]-[21] and IFN- $\gamma$ [18]-[21]. It is interesting to note that both Len and CAM have some common effects on cytokine induction and inhibition. Possibly, they have synergistic effects on MM cells.

Glucocorticoids have been frequently used in the treatment of MM and are known to reduce cellular proliferation partly by downregulating IL-6R and to induce cell cycle arrest and apoptosis [27]. Gandhi et al. demonstrated that Len plus Dex synergistically induced expression of the tumor suppressor genes such as Egr-1, Egr-2, Egr-3, p15, p21, and p27 in MM cell lines and suggested that the combination might have activated caspase 3, 8 and 9 and induced cell cycle arrest and apoptosis [28]. Recently, steroid-enhancing effect or steroid-sparing effect of CAM has been reported. In this connection, Fost et al. demonstrated that administration of CAM with methyl-PSL (m-PSL) resulted in a 65\% reduction of m-PSL clearance and significantly higher mean plasma m-PSL concentrations compared with pre-CAM concentrations [29]. It should be noted that Dex is metabolized by CYP 3A4 [30] and CAM is known to be an inhibitor of CYP 3A4 [31]. It is reasonable to assume that CAM prolongs the half-life of Dex in the serum. Steroid-enhancing effect or steroid-sparing effect of CAM can be explained by the inhibition of CYP 3A4 by CAM.

The clinical course of the present case seems to underlie the mechanism of action of CAM. In our present case, doses of Len and Dex were considerably reduced comparing with BiRD regimen [4] [8] [9], nevertheless, the low Rd therapy was found to be effective. However, the patient became refractory to this regimen approximately 2 and half years after the initiation of the treatment (Figure 4). Thus, CAM was added to low Rd (low Rd-CAM), and the drastic reduction of IgA occurred. Unfortunately, the treatment was interrupted for 3 months because of pneumonitis. During the cessation of the treatment, IgA gradually started to increase up to $946 \mathrm{mg} / \mathrm{dL}$. After recovering from pneumonitis, Len combined with CAM (low R-CAM) regimen was applied. However, this Dex-free regimen was not so effective than expected. Thus, low Rd-CAM therapy was applied again. Its effect was satisfactory; IgA levels decreased to normal (794 mg to $373 \mathrm{mg} / \mathrm{dL}$ ) after one cycle of low Rd-CAM therapy. The clinical course of the present case clearly shows that low Rd-CAM regimen is the favorable combination, and Dex is requisite for this regimen because the omission of Dex resulted in the lower than expected reduction of IgA. It seems that CAM cannot sufficiently play its role without Dex.

CAM has been reported to induce apoptosis through Fas-Fas ligand pathway [32]. Mizunoe et al. demonstrated that CAM induced apoptosis of activated lymphocytes via downregulation of Bcl-xL [33]. Recently, we also demonstrated the apoptotic effect of CAM in a case of sarcoidosis which was successfully treated with CAM [21]. Thus, it is likely that CAM might have further induced apoptosis in Rd-CAM therapy. More recently, Nakamura et al. reported that CAM can attenuate autophagy in MM cells, leading to cell death [34].

As for a single treatment by CAM for MM, Moreau et al. found no response in 35 patients receiving CAM without steroids as a continuous course of 500 to $1000 \mathrm{mg}$ for 4 to 20 weeks (median 8 weeks); MM progressed in $80 \%$ of cases, requiring other therapeutic approaches [35]. Musto et al. reported that the use of CAM for the treatment of advanced MM; among the 38 evaluable patients with relapsed or resistant multiple myeloma, objective or minor responses occurred in one and two patients, respectively [36]. Stewart et al. reported no significant response among 20 evaluable MM patients in various phases of disease treated with CAM alone [37]. The general consensus seems to be that a single CAM treatment has no efficacy in patients with MM.

IL-6 is a key cytokine of myeloma cell proliferation, and is known to increase in MM [38]. The role of IL-6 as a growth and survival factor in MM is well established. Myeloma cells are stimulated to proliferate in response to IL-6. It is known that some myeloma cells can produce their own IL-6, but bone marrow stromal cells are considered to be the main source of IL-6. The orchestration of IL-6-induced signaling pathways contributes to the pleiotropic effects of IL-6 with regard to proliferation, survival, drug resistance and migration of myeloma cells, thereby facilitating disease progression [38]. In the present case, we examined various serum cytokines and observed contradictory results; IL-6 was distinctly elevated during low Rd-CAM treatment, being accompanied by slight elevation of s-IL-2R and CRP. Slightly elevated levels of TNF- $\alpha$ and TGF- $\beta$, though on one occasion, were also seen during low Rd-CAM treatment. Meanwhile most of the cytokines during the treatment-free period remained within normal range (Table 1, Table 2). S-IL-2R is a marker indicating immune activation and is known to increase in lymphoid malignancies, autoimmune diseases, rheumatoid diseases and some infectious diseases. The fact that s-IL-2R increased during low Rd-CAM treatment seems to indicate that immune activation occurred during this treatment. In this connection, Marriott et al. reported the elevation of serum TNF- $\alpha$ and 
s-IL-2R during Len treatment of patients with advanced cancer, and considered that augmentation of TNF- $\alpha$ was due to enhanced T-cell co-stimulation by Len [39]. Len is known to be a potent inhibitor of TNF- $\alpha$ [4] [12] [13]; however, it is possible that serum TNF- $\alpha$ can be increased through T-cell co-stimulation by Len in some situations. In the present case, IL-6, TNF- $\alpha$, TGF- $\beta$, s-IL-2R and CRP increased to varying extent during low Rd-CAM treatment. Increased s-IL-2R might have reflected enhanced T-cell activation, leading to the elevations of some cytokines and related parameters. It is well known that there is a close relationship between IL-6 and CRP; the latter is known to be induced in hepatocytes by IL-6. Thus, the elevated CRP levels seems to be caused by increased IL-6 during low Rd-CAM treatment.

Development of transient inflammatory reactions, such as high fever and elevation of CRP were occasionally seen in MM patients during Rd therapy [40]. Harada et al. examined serum levels of Th1 (IL-2 and IFN- $\gamma$ ) and Th2 (IL-6 and TNF- $\alpha$ ) cytokines in 9 MM patients treated with Len plus Dex, and reported that 6 patients showed elevation of CRP after initiation of the therapy. In these 6 patients, IFN- $\gamma$, IL- 6 and TNF- $\alpha$ were elevated in two, three and one patients, respectively. They also experimentally demonstrated that Len enhanced the production of both Th1 and Th2 cytokines in normal peripheral blood mononuclear cells and in patient bone marrow mononuclear cells, and suggested that the modulation of these cytokine production by Len may contribute to transient inflammatory reaction in MM patients [41]. On the other hand, Morita et al. examined serum cytokine levels in 8 relapsed MM patients undergoing febrile reactions to Len and reported that levels of TNF- $\alpha$ and IL-6 were depressed in most cases after the treatment and IL-6 is not always related to CRP levels in MM patients treated with Len. They reported no significant correlation between the clinical response and rate of reduction of serum IL-6 and TNF- $\alpha$ [42]. Although the cytokine release syndrome was absent in our present case, the fact that transient inflammatory reactions may occur in some MM cases treated with Rd might have complicated the evaluation of serum cytokine values. Furthermore, the evaluation of serum cytokine levels and clinical response to the treatment seems far more complicated because two or three immunomodulatory agents, i.e., Len, Dex and/or CAM, are involved in the treatment. However, the serum cytokine levels do not necessarily reflect the reactions occurred in localized lesions such as bone marrow and extramedullary lesions. Further investigations in serum cytokine levels as well as localized cytokine response in MM cases are needed.

Several studies comparing the effect of Len combined with high- or low-dose of Dex in newly diagnosed MM patients [6] [7] favored the use of low-dose Dex. Len is known to enhance the activity of T cells and NK cells, which may contribute to its clinical antimyeloma effects [12]-[14]. When Len is administrated concomitantly with Dex, the latter enhances the antiproliferative effects of Len but suppresses its immunomodulatory effects in a dose-dependent manner [28]. A regimen of Len plus low-dose Dex may therefore inhibit myeloma cell proliferation while still allowing Len to enhance T cell and NK cell activity. In our present case, both Len and Dex were reduced in consideration of the patient's advanced age, deaf-mutism and moderate mental retardation. Nevertheless, the treatment worked well in reducing M-protein without unfavorable adverse effects. Furthermore, we applied the standard dose of CAM (a dose of $400 \mathrm{mg}$ per day) under 3 weeks on and 1 week off schedule, and succeeded in obtaining a satisfactory response. This indicates that low Rd-CAM regimen seems effective, and continuous high-dose of CAM applied in BiRD [4] [8] [9] is not necessary for treating MM.

In the present case, the myeloma cells obtained on admission showed low cytoplasmic M-proteins and depressed mitotic activity. However, subsequent bone marrow examinations showed distinct cytoplasmic M-proteins in myeloma cells (not shown). The significance of these findings remains unknown, but it might be related to satisfactory response to the treatments.

\section{Conclusion}

The present case was successfully treated with low Rd and low Rd-CAM for a long period of time. Analysis of the clinical course shows that CAM has steroid-sparing/enhancing effect and Dex is requisite for low Rd-CAM regimen. Since both Len and CAM have some common effects on cytokine induction and inhibition in many points, it is probable that they can synergistically effect together with Dex on MM cells. In addition, we emphasize the good efficacy and tolerability of the regimen consisting of low-dose Len, low-dose Dex and conventional dose of CAM. Analyses of serum cytokines and related parameters showed contradictory result; IL-6, TNF- $\alpha$, TGF- $\beta$, CRP and s-IL-2R were elevated in varying degrees during low Rd-CAM. Elevation of s-IL-2R during the treatment may reflect the immune activation, leading to the elevation of some cytokines and related parameters. 


\section{Acknowledgements}

The authors would like to thank Prof. H. K. Ooi (School of Veterinary Medicine, Azab University) for helpful reviewing and preparation of the manuscript.

\section{Conflict of Interests}

All authors declare no conflict of interests.

\section{References}

[1] Dimopoulos, M., Spencer, A., Attal, M., et al. (2007) Lenalidomide plus Dexamethasone for Relapsed or Refractory Multiple Myeloma. The New England Journal of Medicine, 357, 2123-2132. http://dx.doi.org/10.1056/NEJMoa070594

[2] Dimopoulos, M.A., Chen, C., Spencer, A., et al. (2009) Long-Term Follow-Up on Overall Survival from the MM-009 and MM-010 Phase III Trials of Lenalidomide plus Dexamethasone in Patients with Relapsed or Refractory Multiple Myeloma. Leukemia, 23, 2147-2152. http://dx.doi.org/10.1038/leu.2009.147

[3] Rajkumar, S.V., Hayman, S.R., Lacy, M.Q., et al. (2005) Combination Therapy with Lenalidomide plus Dexamethasone (Rev/Dex) for Newly Diagnosed Myeloma. Blood, 106, 4050-4053. http://dx.doi.org/10.1182/blood-2005-07-2817

[4] Richardson, P., Mitsiades, C., Laubach, J., et al. (2009) Lenalidomide in Multiple Myeloma: An Evidence-Based Review of Its Role in Therap. Core Evidence, 4, 215-245. http://dx.doi.org/10.2147/CE.S6002

[5] Zonder, J.A., Crowley, J., Hussein, M.A., et al. (2010) Lenalidomide and High-Dose Dexamethasone Compared with Dexamethasone as Initial Therapy for Multiple Myeloma: A Randomized Southwest Oncology Group Trial (S0232). Blood, 116, 5838-5841. http://dx.doi.org/10.1182/blood-2010-08-303487

[6] Dimopoulos, M.A. and Terpos, E. (2010) Lenalidomide: An Update on Evidence from Clinical Trials. Blood Reviews, 24, 521-526. http://dx.doi.org/10.1016/S0268-960X(10)70005-9

[7] Rajkumar, S.V., Jacobus, S., Callander, N., et al. (2010) Lenalidomide plus High-Dose Dexamethasone versus Lenalidomide plus Low-Dose Dexamethasone as Initial Therapy for Newly Diagnosed Multiple Myeloma: An Open-Label Randomized Controlled Trial. Lancet Oncology, 11, 29-37. http://dx.doi.org/10.1016/S1470-2045(09)70284-0

[8] Niesvitzky, R., Jayabalan, D.S., Christos, P.J., et al. (2008) BiRD (Biaxin [Clarithromycin]/Revlimid [Lenalidomide]/ Dexamethasone) Combination Therapy Results in High Complete- and Overall-Response Rates in Treatment-Naive Symptomatic Multiple Myeloma. Blood, 111, 1101-1109. http://dx.doi.org/10.1182/blood-2007-05-090258

[9] Gay, F., Rajikumar, S.V., Coleman, M., et al. (2010) Clarithromycin (Biaxin)-Lenalidomide-Low-Dose Dexamethasone (BiRd) versus Lenalidomide-Low-Dose Dexamethasone (Rd) for Newly Diagnosed Myeloma. American Journal of Hematology, 85, 664-669. http://dx.doi.org/10.1002/ajh.21777

[10] Čulić, O., Eracović, V. and Parnham, M.J. (2001) Anti-Inflammatory Effects of Macrolide Antibiotics. European Journal of Pharmacology, 429, 209-229. http://dx.doi.org/10.1016/S0014-2999(01)01321-8

[11] Kanoh, S. and Rubin, B.K. (2010) Mechanisms of Action and Clinical Application of Macrolides as Immunomodulatory Medications. Clinical Microbiology Reviews, 23, 590-615. http://dx.doi.org/10.1128/CMR.00078-09

[12] Quach, H., Richie, D., Stewart, A.K., Neeson, P., Harrison, S., Smyth, M.J. and Prince, H.M. (2010) Mechanism of Action of Immunomodulatory Drugs (IMiDS) in Multiple Myeloma. Leukemia, 24, 22-32. http://dx.doi.org/10.1038/leu.2009.236

[13] Vallet, S., Palumbo, A., Raje, N., Boccadoro, M. and Anderson, K.C. (2008) Thalidomide and Lenalidomide: Mechanism-Based Potential Drug Combinations. Leukemia \& Lymphoma, 49, 1238-1245. http://dx.doi.org/10.1080/10428190802005191

[14] Xu, Y.B., Sun, J., Sheard, M.A., Tran, H.C., Wan, Z.S., Liu, W.Y., et al. (2013) Lenalidomide Overcomes Suppression of Human Natural Killer Cell Anti-Tumor Functions by Neuroblastoma Microenvironment-Associated IL-6 and TGF $\beta 1$. Cancer Immunology, Immunotherapy, 62, 1637-1648. http://dx.doi.org/10.1007/s00262-013-1466-y

[15] Lu, G., Middleton, R.E., Sun, H., Naniong, M., Ott, C.J., Mitsiades, C.S., et al. (2014) The Myeloma Drug Lenalidomide Promotes the Cereblon-Dependent Destruction of Ikaros Proteins. Science, 343, 305-309. http://dx.doi.org/10.1126/science.1244917

[16] Krönke, J., Udeshi, N.D., Narla, A., Grauman, P., Hurst, S.N., McConkey, M., et al. (2014) Lenalidomide Causes Selective Degradation of IKZF1 and IKZF3 in Multiple Myeloma Cells. Science, 343, 301-305. http://dx.doi.org/10.1126/science.1244851

[17] Sakamoto, M., Mikasa, K., Hamada, K., et al. (1996) Long-Term Clarithromycin Treatment for Cancer Cachexia of Inoperable Non-Small Cell Lung Cancer Patients. Japanese Journal of Chemotherapy, 44, 879-882. 
[18] Majima, T., Mikasa, K., Hamada, K., Konishi, M., Maeda, K., Sakamoto, M., et al. (1999) Changes of Cytokine mRNA in Peripheral Blood Mononuclear Cells from Unresectable Non-Small Cell Lung Cancer Patients before and after Clarithromycin Therapy. Japanese Journal of Chemotherapy, 47, 345-348.

[19] Hamada, K., Mikasa, K., Yunou, Y., Kurioka, T., Majima, T., Narita, N. and Kita, E. (2000) Adjuvant Effect of Clarithromycin on Chemotherapy for Murine Lung Cancer. Chemotherapy, 46, 49-61. http://dx.doi.org/10.1159/000007256

[20] Majima, T., Mikasa, K., Sakamoto, M., Hamada, K., Konishi, M., Maeda, K., et al. (2000) Clarithromycin Regulates Cytokine mRNA in Non-Small Cell Lung Cancer. Japanese Journal of Chemotherapy, 48, 780-785.

[21] Takemori, N., Nakamura, M., Kojima, M. and Eishi, Y. (2014) Successful Treatment in a Case of Propionibacterium acnes-Associated Sarcoidosis with Clarithromycin Administration: A Case Report. Journal of Medical Case Reports, 8, 15. http://dx.doi.org/10.1186/1752-1947-8-15

[22] Takeshita, K., Yamagishi, I., Harada, M., Otomo, S., Nakagawa, T. and Mizushima, Y. (1989) Immunological and Anti-Inflammatory Effects of Clarithromycin: Inhibition of Interleukin 1 Production of Murine Peritoneal Macrophages. Drugs under Experimental and Clinical Research, 15, 527-533.

[23] Morikawa, K., Zhang, J., Nonaka, M. and Morikawa, S. (2002) Modulatory Effect of Macrolide Antibiotics on the Th1- and Th2-Type Cytokine Production. International Journal of Antimicrobial Agents, 19, 53-59. http://dx.doi.org/10.1016/S0924-8579(01)00457-5

[24] Sugiyama, K., Shirai, R., Mukae, H., Ishimoto, H., Nagata, T., Sakamoto, N., et al. (2007) Differing Effects of Clarithromycin and Azithromycin on Cytokine Production by Murine Dendritic Cells. Clinical \& Experimental Immunology, 147, 540-546. http://dx.doi.org/10.1111/j.1365-2249.2007.03299.X

[25] Kikuchi, T., Hagiwara, K., Honda, Y., Gomi, K., Kobayashi, T., Takahashi, H., et al. (2002) Clarithromycin Suppresses Lipopolysaccharide-Induced Interleukin-8 Production by Human Monocytes through AP-1 and NF- $\kappa$ B Transcription Factors. Journal of Antimicrobial Chemotherapy, 49, 745-755. http://dx.doi.org/10.1093/jac/dkf008

[26] Sassa, K., Mizushima, Y. and Kobayashi, M. (1999) Differential Modulatory Effects of Clarithromycin on the Production of Cytokines by a Tumor. Antimicrobial Agents and Chemotherapy, 43, 2787-2789.

[27] Greenstein, S., Ghias, K., Krett, N.L. and Rosen, S.T. (2002) Mechanisms of Glucocorticoid-Mediated Apoptosis in Hematological Malignancies. Clinical Cancer Research, 8, 1681-1694.

http://clincancerres.aacrjournals.org/content/8/6/1681.long

[28] Gandhi, A.K., Kang, J., Capone, L., Parton, A., Wu, L., Zhang, L.H., et al. (2010) Dexamethasone Synergizes with Lenalidomide to Inhibit Multiple Myeloma Tumor Growth, but Reduces Lenalidomide-Induced Immunomodulation of T and NK Cell Function. Current Cancer Drug Targets, 10, 155-167. http://dx.doi.org/10.2174/156800910791054239

[29] Fost, D.A., Leung, D.Y.M., Martin, R.J., Brown, E.E., Szefler, S.J. and Spahn, J.J. (1999) Inhibition of Methylprednisolone Elimination in the Presence of Clarithromycin Therapy. Journal of Allergy and Clinical Immunology, 103, 1031-1035. http://dx.doi.org/10.1016/S0091-6749(99)70175-2

[30] Gentile, D.M., Tomlinson, E.S., Maggs, J.L., Park, B.K. and Back, D.J. (1996) Dexamethasone Metabolism by Human liver in Vitro. Metabolite Identification and Inhibition of 6-hydroxylation. The Journal of Pharmacology and Experimental Therapeutics, 277, 105-112.

[31] Pint, A.G., Wang, Y.H., Chalasani, N., Skaar, T., Kolwankar, D., Gorski, J.C., et al. (2005) Inhibition of Human Intestinal Wall Metabolism by Macrolide Antibiotics: Effect of Clarithromycin on Cytochrome P450 3A4/5 Activity and Expression. Clinical Pharmacology \& Therapeutics, 77, 178-188. http://dx.doi.org/10.1016/j.clpt.2004.10.002

[32] Ishimatsu, Y., Kadota, J., Iwashita, T., Nagata, T., Ishii, H., Shikuwa, C., et al. (2004) Macrolide Antibiotics Induce Apoptosis of Human Peripheral Lymphocytes in Vitro. International Journal of Antimicrobial Agents, 24, 247-253. http://dx.doi.org/10.1016/j.ijantimicag.2004.03.022

[33] Mizunoe, S., Kadota, J., Tokimatsu, I., Kishi, K., Nagai, H. and Nasu, M. (2004) Clarithromycin and Azithromycicn Induce Apoptosis of Activated Lymphocytes via Down-Regulation of Bcl-xL. International Immunopharmacology, 4, 1201-1207. http://dx.doi.org/10.1016/j.intimp.2004.05.011

[34] Nakamura, M., Kikukawa, Y., Takeya, M., Mitsuya, H. and Hata, H. (2010) Clarithromycicn Attenuates Autophagy in Myeloma Cells. International Journal of Oncology, 37, 815-820.

[35] Moreau, P., Huynh, A., Facon, T., Bouilly, I., Sotto, J.J., Legros, L., et al. (1999) Lack of Efficacy of Clarithromycin in Advanced Multiple Myeloma. Leukemia, 13, 490-491. http://dx.doi.org/10.1038/sj.leu.2401332

[36] Musto, P., Falcone, A., Sanpaolo, G., Bodenizza, C., Carotenuto, M. and Carella, A.M. (2002) Inefficacy of Clarithromycic in Advanced Multiple Myeloma: A Definitive Report. Haematologica, 87, 658-659. http://www.haematologica.ws/2002 06/658.htm

[37] Stewart, A.K., Trudel, S., Al-Berouti, B.M., Sutton, D.M. and Meharchand, J. (1999) Lack of Response to Short-Term Use of Clarithromycin (Biaxin) in Multiple Myeloma. Blood, 93, 4441-4449. 
[38] Burger, R. (2013) Impact of Interleukin-6 in Hematological Malignancies. Transfusion Medicine and Hemotherapy, 40, 336-343. http://dx.doi.org/10.1159/000354194

[39] Marriott, J.B., Clarke, I.A., Dredge, K., Muller, G., Stirling, D. and Dalgleish, A.G. (2002) Thalidomide and Its Analogues Have Distinct and Opposing Effects on TNF- $\alpha$ and TNFR2 during Co-Stimulation of both CD4 ${ }^{+}$and CD8 ${ }^{+} \mathrm{T}$ Cells. Clinical \& Experimental Immunology, 130, 75-84. http://dx.doi.org/10.1046/j.1365-2249.2002.01954.X

[40] Nakamura, N., Kanemura, N., Shibata, Y., Matsumoto, T., Mabuchi, R., Nakamura, H., et al. (2014) LenalidomideInduced Cytokine Release Syndrome in a Patient with Multiple Myeloma. Leukemia \& Lymphoma, 55, 1691-1693. http://dx.doi.org/10.3109/10428194.2013.853300

[41] Harada, T., Ozaki, S., Oda, A., Fujii, S., Nakamura, S., Miki, H., et al. (2013) Association of Th1 and Th2 Cytokines with Transient Inflammatory Reaction during Lenalidomide Plus Dexamethasone Therapy in Multiple Myeloma. International Journal of Hematology, 97, 743-748. http://dx.doi.org/10.1007/s12185-013-1321-0

[42] Morita, Y., Shimada, T., Yamaguchi, T., Rai, S., Hirase, C., Emoto, M., et al. (2011) Cytokine Profiles in Relapsed Multiple Myeloma Patients Undergoing Febrile Reactions to Lenalidomide. International Journal of Hematology, 94, 583-584. http://dx.doi.org/10.1007/s12185-011-0973-x 
Scientific Research Publishing (SCIRP) is one of the largest Open Access journal publishers. It is currently publishing more than 200 open access, online, peer-reviewed journals covering a wide range of academic disciplines. SCIRP serves the worldwide academic communities and contributes to the progress and application of science with its publication.

Other selected journals from SCIRP are listed as below. Submit your manuscript to us via either submit@scirp.org or Online Submission Portal.
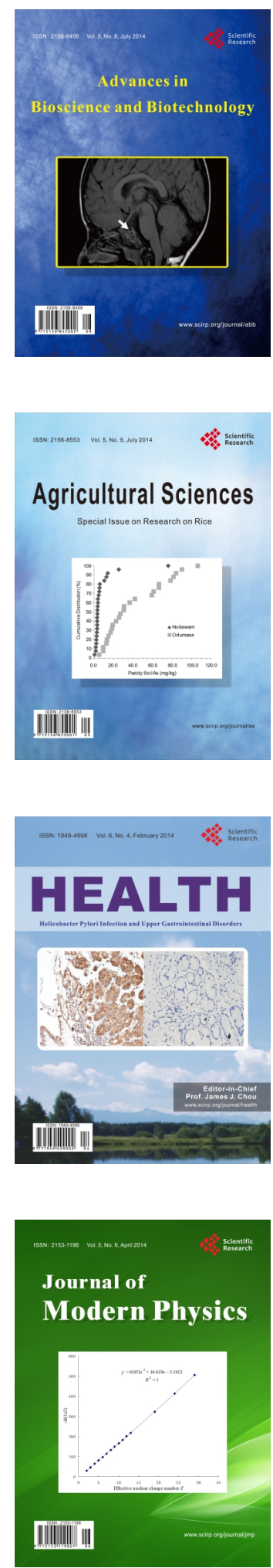
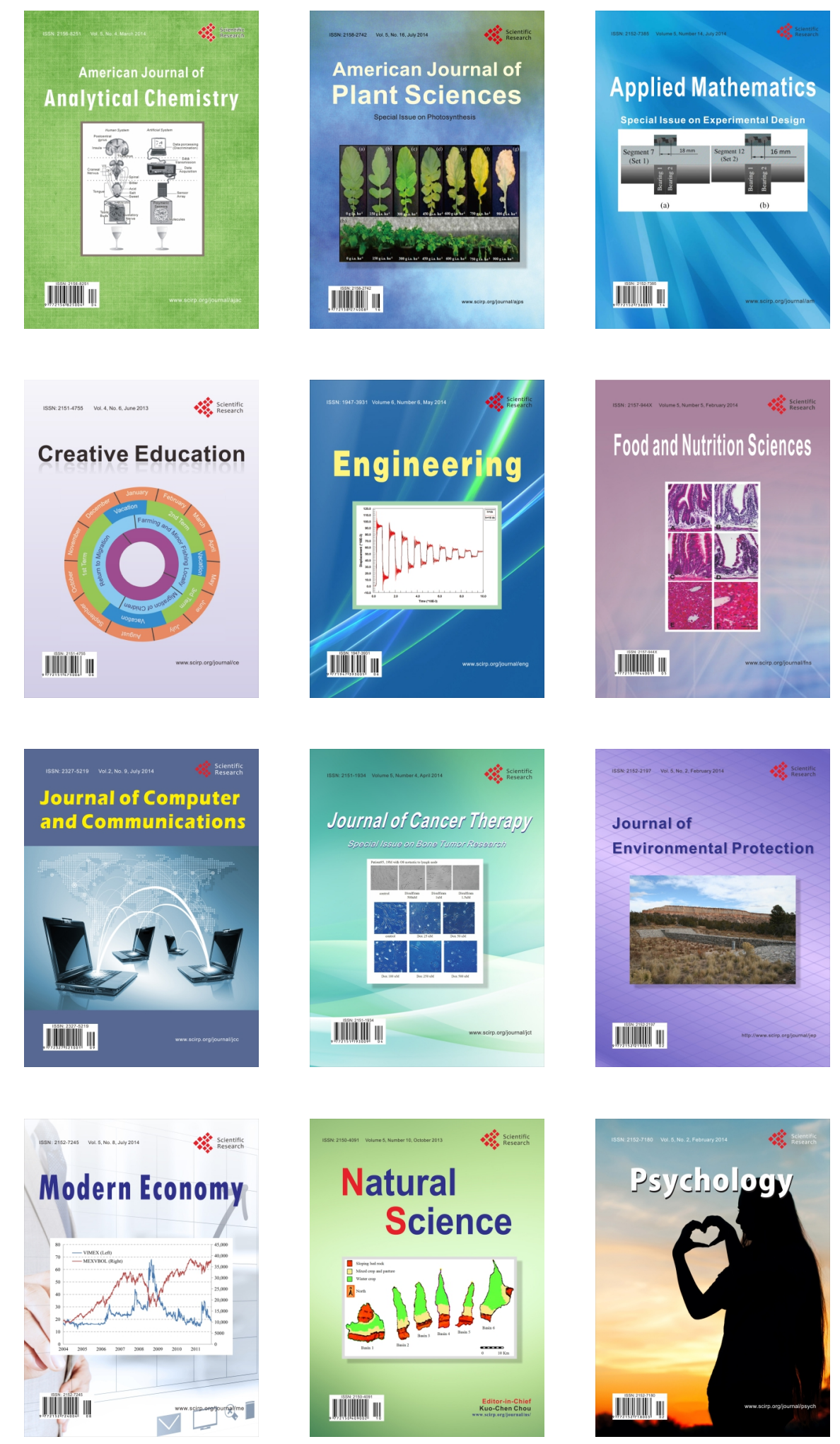